\title{
Commentary
}

See article on page 452

\section{The aging stomach or the stomachs of the ages}

Although few would challenge the role of Helicobacter pylori as a major gastroduodenal pathogen, many paradoxes remain. Infection is mainly acquired in childhood, yet the major symptomatic diseases, peptic ulcer and gastric cancer, occur predominantly in adults or the elderly. Patterns of disease vary within and between different populations. In some countries, the incidence of duodenal ulcer is high whereas in others the progression of $H$ pylori associated pathology is more towards gastric ulcer and adenocarcinoma. These patterns of disease are changing in certain countries and this seems to correlate with improvements in socioeconomic status. Thus in the United Kingdom and the United States, peptic ulcer and gastric cancer were rare before the 19 th century. ${ }^{12}$ From the middle 1800 s, gastric ulcer and cancer increased and by the early 1900 s duodenal ulcers appeared and slowly started to surpass gastric ulcers in frequency. In more recent times, there has been a decline in the frequency of carcinoma, and both types of ulcer while reflux oesophagitis seems to be on the increase. In the less developed world, in countries such as Colombia and China, these changes have been delayed and gastric cancer remains a frequent cause of death.

Given that $H$ pylori is an aetiological factor in both ulcer disease and gastric malignancy, how can these temporal and geographical trends be reconciled? One of us had postulated differences in acid output as the explanation. ${ }^{3}$ Higher acid restricts growth of $H$ pylori and inflammation to the antrum while lower acid allows the bacterium to thrive in the body, inducing a pangastritis. We predicted that the mean local acid output in those populations with the gastric ulcer/gastric cancer profile would be less than in populations more prone to duodenal ulcer. Moreover, in those countries which are undergoing rapid improvements in the standard of living and where there is a change in the gastric:duodenal ulcer ratio, one would predict that acid output now would be higher than it was decades ago, independent of $H$ pylori infection. Japan is just such a country and the article by Kinoshita et al in this issue (see page 452) is the first published data on such changes in acid secretion. These authors looked at comparable groups of $H$ pylori infected or non-infected non-elderly patients $(<65$ years) and elderly patients ( $>65$ years) who had comprehensive gastric acid analysis performed in either the early 1970 s or the 1990s. Although there are inevitable problems with such a retrospective study design, the data show that acid secretion in the $1990 \mathrm{~s}$ was higher in both the non-elderly and elderly regardless of $H$ pylori infection when measured as either basal acid output (BAO) after a 12 hour fast or as maximal acid output (MAO) measured over one hour following stimulation with $6 \mu \mathrm{g}$ pentagastrin. Even though these acid output levels still are not as high as those seen in Western populations where duodenal ulcer is more prevalent, there is a clear trend towards higher acid output in Japan. If the acid hypothesis is correct, we would expect the incidence of gastric ulcer and gastric cancer in Japan to go down and eventually the incidence of duodenal ulcer to rise. Certainly, there is a decline in the incidence of gastric ulcer and cancer. The data on changes in duodenal ulcer are harder to find. However, in a study of peptic ulcer disease mortality, the gastric:duodenal ulcer ratio in Japan was 8.9 in $1960-68,6.4$ in $1970-78$ and 4.7 in $1980-89 .{ }^{4}$ Consistent with the change in acid impacting on gastric disease is the observation in another study, of a significantly lower mean age of duodenal ulcer diagnosis (40.7) compared with gastric ulcer (53.7). ${ }^{5}$

How is it that an increased acid output effects $H$ pylori associated disease? How is this relevant to the appearance of peptic ulcers less than 200 years ago and changes in the patterns of these diseases in world populations over recent times?

$H$ pylori infection as the symptomatic gastric diseases of civilisation

Over the millennia of evolution of the human stomach, the ability to produce acid was an adaptation to facilitate the digestion of ingested nutrients but at the same time provided a defence mechanism against ingested bacterial pathogens. Most bacteria are acid sensitive but one group of organisms learnt to survive local gastric acid. These were the gastric helicobacters. To do this, the microorganisms acquired a specialised urease enzyme that neutralised local acid via generation of ammonia which mopped up local protons, thus preserving the energy generating proton motive force of the bacterium. ${ }^{6}$

In the beginning, $H$ pylori was normal flora of the human stomach just as Bacteroides spp were normal flora of the lower bowel. Even though the bacterium induced a significant gastritis in its human host this was of no consequence as, due to particular diets, overall nutrition, and coinfection with bacterial pathogens and parasites (all factors likely to reduce gastric acidity), the acid output was simply not enough to induce ulcer formation. Gastric cancer was rarely seen as life expectancy was just not long enough for tumour development.

Then, in the industrialised societies of the world, the living conditions of many improved. Nutrition was better, the parasite burden decreased, diets changed, and so acid output increased. In some, the acid load now impinging on the $H$ pylori inflamed mucosa passed a threshold such that a small focus of epithelial damage could occur, setting the scene for ulcer formation. Thus gastric ulcers started to appear. Other factors, such as smoking, facilitated this process. As life expectancy increased, so did the chance of long term damage caused by $H$ pylori induced inflammation on the corpus mucosa. Atrophy and hypochlorhydria together with dietary factors predisposed to gastric cancer.

With the passage of time, the health and welfare of the wealthy increased such that a new gastric scenario appeared. Ever improving nutrition and hygiene resulted in lack of microbial infection, the acid output improved such that their $H$ pylori could not thrive as well in the acid secreting body mucosa, thus gastritis was confined to the antrum and gastric ulcer and cancer were unlikely. However, now excess acid impinging on the duodenal bulb induced the formation of islets of gastric metaplasia which became the focus of $H$ pylori infection. In some cases the 
resulting duodenitis progressed to duodenal ulcer. This is why in the USA and the United Kingdom in the 1930s, duodenal ulcer disease was described as a disease of the wealthy. ${ }^{7}$ Into the 1950 s and 1960 s, the overall health of the developed societies resulted in an increase in duodenal ulcer disease and a decline in gastric ulcer. More recently, another consequence of improved hygiene has been the loss of childhood infection with $H$ pylori. Hence a decline in those populations of not only gastric ulcer and cancer but of peptic ulcer in general. An increasingly possible outcome in these $H$ pylori free populations is that as a consequence of the increased acid output discussed above, gastrooesophageal disease will increase. ${ }^{8}$ These social impacts have been delayed in Japan but predictably the dramatic changes in the standard of living post war is being reflected in changes in the patterns of gastroduodenal disease. The observations of the paper by Kinoshita et al on changes in acid production over time seem to make the these ideas tenable.

There are other observations in this paper which raise issues pertinent to the focus of this issue of the journal on aging. In both the Japanese patients in the 1970s and 1990s, there does seem to be a decrease in acid output with aging, independent of $H$ pylori infection. These data are hard to interpret due to the known fall off in the predictive ability of serology to document $H$ pylor $i$ infection with age and seem in conflict with studies from Australia and the USA. ${ }^{9}{ }^{10}$ However, if these changes in the aging stomach do occur independently of infection, then due to the reasons outlined earlier they will impact on the outcome of the disease in those that are infected.

Kinoshita et al's paper is the first comparative study to describe changes in acid secretion in similar populations at different time points which reflect a period of rapid economic growth. It should be a stimulus for the search for equivalent hidden data in other countries which will then contribute to our understanding of the apparent paradoxes of $H$ pylori associated disease and determine the relative importance of the aging stomach or the stomachs of the ages.

School of Microbiology and Immunology,

ADRIAN LEE

The University of New South Wales,

Sydney, Australia

SANDER VELDHUYZEN VAN ZANTEN

Division of Gastroenterology,

Dalhousie University,

Victoria General Hospital,

Halifax, Canada

Correspondence to: Professor Lee.

Adrian Lee's research is supported by the National Health and Medical Research Council of Australia. Sander Veldhuyzen van Zanten holds a career award from the Pharmaceutical Manufacturers Association of Canada/Medical Research Council.

1 Bonnevie O. Changing demographics of peptic ulcer disease. Dig Dis Sci 1985; 30 (suppl 11): 8S-14S

2 Sonnenberg A. Temporal trends and geographical variations of peptic ulcer disease. Aliment Pharmacol Ther 1995; 9 (suppl 2): 3-12.

3 Lee A, Dixon MF, Danon SJ, Kuipers E, Megraud F, Larsson H, et al. Local acid production and Helicobacter pylori: a unifying hypothesis of gastroduodenal disease. Eur $\mathcal{F}$ Gastroenterol Hepatol 1995; 7: 461-5.

4 Kurata J, Nogawa A, Watanabe Y, Kawai K. Peptic ulcer disease mortality. Comparison of native Japanese, Japanese Americans and Caucasian Americans. $\mathcal{F}$ Clin Gastroenterol 1994; 18: 145-54.

5 Watanabe Y, Kurata JH, Kawamoto K, Kawai K. Epidemiological study of peptic ulcer disease among Japanese and Koreans in Japan. 7 Clin Gastroenterol 1992; 15: 68-74.

6 Meyer Rosberg K, Scott DR, Rex D, Melchers K, Sachs G. The effect of environmental $\mathrm{pH}$ on the proton motive force of Helicobacter pylori. Gasenvironmental $\mathrm{pH}$ on the proton

7 Anonymous. Gastric ulcer and the ulcer equation. Lancet 1959; i: 1131-3.

8 Penston JG. Review article: clinical aspects of Helicobacter pylori eradication therapy in peptic ulcer disease. Aliment Pharmacol Ther 1996; eradication

9 Katelaris PH, Seow F, Lin BPC, Napoli J, Ngu MC, Jones DB. Effect of age, Helicobacter pylori infection, and gastritis with atrophy on serum gastrin and gastric acid secretion in healthy men. Gut 1993; 34: 1032-7.

10 Feldman M, Cryer B, Mcarthur KE, Huet BA, Lee E. Effects of aging and gastritis on gastric acid and pepsin secretion in humans: a prospective study. Gastroenterology 1996; 110: 1043-52. 